\title{
Comparison of Modeling and Simulation Results Management Micro Climate of the Greenhouse by Fuzzy Logic between a Wetland and Arid Region
}

\author{
Didi Faouzi*1 $^{1}$, N. Bibi-Triki ${ }^{2}$, B. Draoui ${ }^{3}$, A. Abène $^{4}$ \\ ${ }^{1 *}$ Faculty of Science and Technology, Department of Physics, University of Abu-Bakr Belkaïd, PB 119, Tlemcen, Algeria \\ ${ }^{2}$ Materials and Renewable Energy Research Unit M.E.R.U University of Abu-Bakr Belkaïd, PB 119, Tlemcen, Algeria \\ ${ }^{3}$ Energy Laboratory in Drylands University of Bechar, BP 417, 08000 Bechar Algeria \\ ${ }^{4}$ Euro-Mediterranean Institute of Environment and Renewable Energies (123ER), University of Valenciennes, France
}

\begin{tabular}{l}
\hline \hline Article Info \\
\hline Article history: \\
Received Sep 15, 2017 \\
Revised Nov 14, 2017 \\
Accepted Nov 23, 2017 \\
\hline Keyword: \\
Fuzzy controller \\
Greenhouse \\
Microclimate \\
Modeling \\
Optimization \\
Simulation \\
\hline
\end{tabular}

\begin{abstract}
Currently the climate computer offers many benefits and solves problems related to the regulation, monitoring and controls. Greenhouse growers remain vigilant and attentive, facing this technological development. they ensure competitiveness and optimize their investments / production cost which continues to grow. The application of artificial intelligence in the industry known for considerable growth, which is not the case in the field of agricultural greenhouses, where enforcement remains timid. it is from this fact, we undertake research work in this area and conduct a simulation based on meteorological data through MATLAB Simulink to finally analyze the thermal behavior -greenhouse microclimate energy . In this paper we present comparison of modeling and simulation management of the greenhouse microclimate by fuzzy logic between a wetland (Dar El Beida Algeria) and the other arid (Biskra Algeria).
\end{abstract}

Copyright (C) 2017 Institute of Advanced Engineering and Science. All rights reserved.

\section{Corresponding Author:}

Didi Faouzi,

Faculty of Science and Technology,

Department of Physics, University of Abu-Bakr Belkaïd, PB 119, Tlemcen, Algeria.

Email: didifouzi19@yahoo.com

\section{INTRODUCTION}

Agricultural greenhouse originally designed as a simple enclosure limited by a transparent wall, as is the case for conventional tunnel greenhouses and largely answered chapel in several countries including those of the Mediterranean basin [21]. They amplify certain characteristics of the surrounding environment, thus involving variations of internal energy and fairly significant heat loss due to the low inertia of the clamp system [7-10]. The first objective is to improve the thermal capacity of the greenhouse (greenhouse) [17-18]. This is, to characterize the behavior of the complex system that is the greenhouse with its various compartments (ground, culture, cover, indoor and outdoor environment). To develop non-stationary mathematical models usable for simulation, optimization and the establishment of laws and control of simple and effective regulation.

These models must reproduce the essential properties of the mechanisms and interactions between different compartments. They must be both specific enough to obey the dynamic and real behavior of the greenhouse system, and fairly small to be easily adaptable to the phases of the simulation. Good modulation instructions depending on the requirements of the plants to grow under shelter and outdoor climatic conditions [8-9], result in a more rational and efficient use of inputs and equip the best production performance. The greenhouse climate is modified by artificial actuators, thus providing the best conditions in the immediate environment of energy costs and it requires a controller, which minimizes the power consumption while keeping the state variables as close as possible optimal harvest [16]. 
In this paper, or using fuzzy logic which is a powerful way to optimize and facilitate the global management of modern greenhouse, while providing through simulation interesting and encouraging which results in an optimization of favorable state variable values for the growth and development of protected cultivation [10-12-13].

\section{EQUATION OF STATE}

\subsection{Energy Balance of the Greenhouse}

The analytical energy balance equation of the greenhouse:

Stored energy change=Gain from internal sources+Gain from the sun-Losses due to conduction through the cover-Losses due to long wave radiation-Unrealized losses (evaporation)-losses due to the exchange of air .

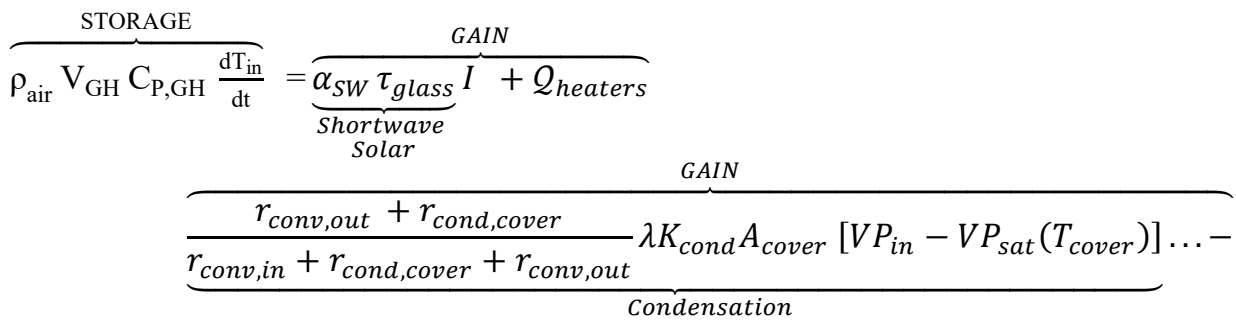

$$
\begin{aligned}
& \overbrace{\underbrace{h_{r, \text { sky }}\left(1-\varepsilon_{\text {cover }}\right)\left(T_{\text {in }}-T_{\text {sky }}\right)-08 \varepsilon_{\text {cover }} h_{r, \text { cver }}\left(T_{\text {in }}-T_{\text {cover }}\right)}_{\text {longwave }}}^{\text {LOSSES }} \cdots- \\
& \text { LOSSES } \\
& \overbrace{\underbrace{A_{\text {floor }} \eta_{\text {utilization }} \frac{\Delta R_{\text {net }}}{\Delta+\gamma}}_{\text {Evapotranspiration }}}^{\text {LOSSES }} \ldots
\end{aligned}
$$

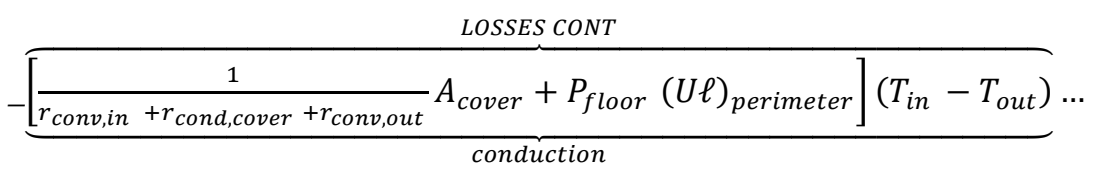

$$
\begin{aligned}
& -\overbrace{\text { Foggers }}^{\overbrace{\underbrace{}_{\text {net }}\left(V P_{\text {sat }}\left(T_{\text {wb }}\left[T_{\text {air }}, r h_{\text {air }}\right]\right)-V P_{\text {air }}\right)}^{\text {LOSSES CON }}}
\end{aligned}
$$

$\mathrm{e}_{\mathrm{sat}} \quad$ : Indicates the report saturated with the relative humidity in the sub-model of combustion

$$
\text { (Kg steam / kg air) }
$$

$\mathcal{Q}_{\text {heaters }} \quad:$ Is the heat provided by the heating system $(\mathrm{W})$

$\mathrm{r}_{\text {conv,in }}, \mathrm{r}_{\text {conv,out }}$ : Heat transfer coefficient inside and outside by convection $\left(\mathrm{W} / \mathrm{m}^{2} . \mathrm{k}\right)$

\subsection{The mass transfer in the greenhouse}

The mass balance for moisture in the greenhouse can be written as following Equation (2) :

$$
\begin{aligned}
& \rho_{\text {air }} V_{\text {greenhouse }} \frac{d e_{\text {in }}}{d t}= \\
& -\dot{V}_{\text {inf }} * \rho_{\text {air }}\left(H_{\text {in }}-H_{\text {out }}\right)-\dot{V}_{\text {vent }} * \rho_{\text {air }}\left(H_{\text {in }}-H_{\text {pad }}\right)+\underbrace{\frac{1}{\lambda} A_{\text {floor }} \eta_{\text {uilization }} \frac{\Delta R_{\text {net }}}{\Delta+\gamma}}_{\text {Evapotranspiration }}- \\
& \underbrace{K_{\text {cond }} A_{\text {cover }}\left[V P_{\text {in }}-V P_{\text {sat }}\left(T_{\text {cover }}\right)\right]}_{\text {condensation }}+\underbrace{K A_{\text {net }}\left(V P_{\text {sat }}\left(T_{w b}\left[T_{\text {air }}, r h_{\text {air }}\right]\right)-V P_{\text {air }}\right)}_{\text {foggers }}+ \\
& \underbrace{r \phi e_{\text {sat }}\left(T_{\text {exhaust }}\right) \frac{Q_{\text {heat }}}{h_{\text {combustion }}}}_{\text {combustion }}
\end{aligned}
$$


$\dot{V}_{\text {inf }} \quad:$ The speed of air infiltration $(\mathrm{m} / \mathrm{s})$

$\mathrm{V}_{\text {greenhouse }}$ : The total volume of agricultural greenhouse $\left(\mathrm{m}^{3}\right)$

$\mathrm{H}_{\mathrm{in}}, \mathrm{H}_{\text {out }} \quad$ : Is the indoor and outdoor humidity $(\mathrm{KJ} / \mathrm{kg})$

$\dot{\mathrm{V}}_{\text {vent }} \quad:$ Ventilation rate $\left(\mathrm{m}^{3}\right.$ air $\left./ \mathrm{s}\right)$

And for the humidity balance:

Rates of change in absolute humidity $=$ Infiltration + Ventilation $*$ (humidity difference with the outside) + Misting + Cooling + AND - Condensation.

The status of humidity function is Equation (3):

$$
\begin{gathered}
\frac{d H_{\text {in }}}{d t} \underbrace{=-n V_{p}\left(H_{\text {in }}-H_{\text {sat }}\right)}_{\text {Ventilation infiltration }}+\underbrace{E}_{\text {fogapotranspiration }}\left(V P_{\text {in }}-V P_{\text {sat,wetbulb }}\right)-K_{\text {condensation }}\left(V P-V P_{\text {sat }}\right) \\
\underbrace{E}_{\text {Evapotranspiration }}: \text { The amount of heat provided by evapotranspiration }(\mathrm{W}) .
\end{gathered}
$$

\section{FUZZY CONTROLLER MODELING}

Fuzzy logic is widely used in the machine control. The term "fuzzy" refers to the fact that the logic can deal with concepts that can not be expressed as the "true" or "false" but rather as "partially true". [15] While alternative approaches such as genetic algorithms and neural networks can perform just as well as fuzzy logic in many cases, fuzzy logic has the advantage that the solution can be cast in terms that human operators can understand, so that their experience can be used in the design of the control device. This makes it easier to mechanize the tasks have already been performed successfully by man [3].

\subsection{Fuzzy Inference Method MAMDANI}

Fuzzy inference Mamdani type, as defined for Toolbox fuzzy logic, expects the output membership functions to be fuzzy sets. After the aggregation process, there is a fuzzy set for each output variable to defuzzification. It is possible, and in some cases much more efficient to use a single peak as output membership function, rather than a distributed fuzzy set. This is sometimes known as singleton output membership function, and we can think like a fuzzy set of pre defuzzification. It improves the efficiency of defuzzification because it greatly simplifies the calculation required by the more general method Mamdani which has the center of gravity of a two-dimensional function. [4-5]

To calculate the output of the SIF in view of inputs, six steps should be followed :

a. The determination of a set of fuzzy rules.

b. Fuzzification inputs using the input membership functions.

c. By combining Fuzzificaion entries according to the fuzzy rules to establish a resistance to the rule.

d. Find the consequence of rule by combining the resistance to the rule and the output membership function.

e. By combining the consequences to get a distribution outlet.

f. Defuzzification the output distribution.

\subsection{Fuzzy Sets}

Please use a 9-point Times Roman font, or other Roman font with serifs, as close as possible in appearance to Times Roman in which these guidelines have been set. The goal is to have a 9-point text, as you see here. Please use sans-serif or non-proportional fonts only for special purposes, such as distinguishing source code text. If Times Roman is not available, try the font named Computer Modern Roman. On a Macintosh, use the font named Times. Right margins should be justified, not ragged.

The input variables in a fuzzy control system are generally mapped by sets of membership functions similar to it, called "fuzzy set". The process of converting a crisp input value to a fuzzy value is called "fuzzy logic". A control system may also have different types of switch, or "ON-OFF", inputs and analog inputs and during switching inputs will always be a truth value of 1 or 0 , but the system can handle as simplified fuzzy functions happen to be one value or another. Given "mappings" of input variables membership functions and truth values, the microcontroller then makes decisions for action on the basis of a set of "rules" . 


\subsubsection{Membership Functions}
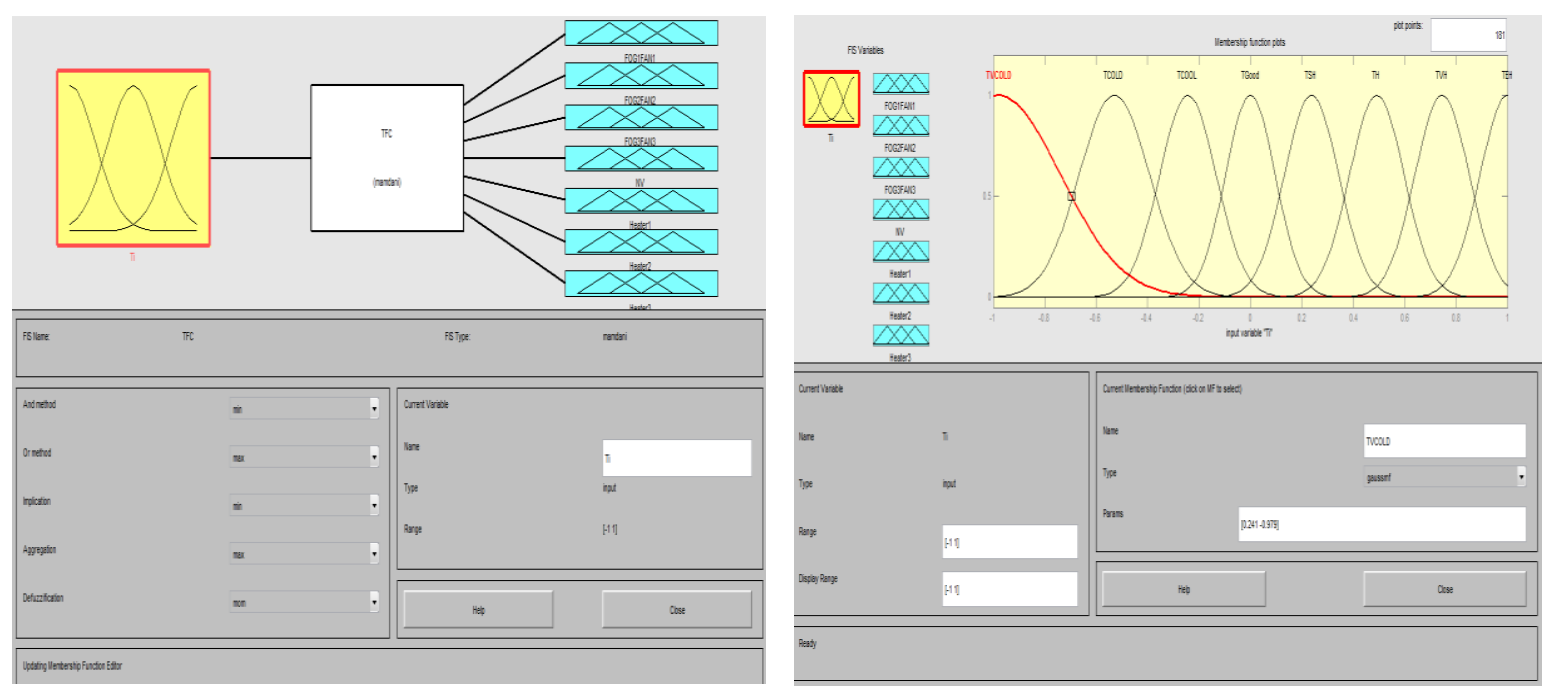

Figure 1. Representation Rules of Membership

\subsubsection{Rules of decisions}

a. If (Ti is TVCOLD) then (FOG1FAN1 is OFF)(FOG2FAN2 is OFF)(FOG3FAN3 is OFF)(NV is $\mathrm{OFF})($ Heater1 is $\mathrm{ON})($ Heater2 is $\mathrm{ON})($ Heater3 is $\mathrm{ON})(1)$

b. If ( $\mathrm{Ti}$ is TCOLD) then (FOG1FAN1 is OFF)(FOG2FAN2 is OFF)(FOG3FAN3 is OFF)(NV is $\mathrm{OFF})($ Heater1 is $\mathrm{ON})($ Heater2 is $\mathrm{ON})($ Heater3 is OFF) (1)

c. If ( $\mathrm{Ti}$ is TCOOL) then (FOG1FAN1 is OFF)(FOG2FAN2 is OFF)(FOG3FAN3 is OFF)(NV is $\mathrm{OFF})($ Heater 1 is $\mathrm{ON})($ Heater2 is $\mathrm{OFF})($ Heater3 is OFF) (1)

d. If (Ti is TSH) then (FOG1FAN1 is OFF)(FOG2FAN2 is OFF)(FOG3FAN3 is OFF)(NV is $\mathrm{ON})($ Heater1 is OFF)(Heater2 is OFF)(Heater3 is OFF) (1)

e. If (Ti is TH) then (FOG1FAN1 is ON)(FOG2FAN2 is OFF)(FOG3FAN3 is OFF)(NV is OFF)(Heater1 is $\mathrm{OFF})($ Heater2 is $\mathrm{OFF})($ Heater3 is OFF) (1)

f. If (Ti is TVH) then (FOG1FAN1 is ON)(FOG2FAN2 is ON)(FOG3FAN3 is OFF)(NV is OFF)(Heater1 is $\mathrm{OFF})($ Heater2 is OFF)(Heater3 is OFF) (1)

g. If (Ti is TEH) then (FOG1FAN1 is ON)(FOG2FAN2 is ON)(FOG3FAN3 is ON)(NV is OFF)(Heater1 is $\mathrm{OFF})($ Heater2 is $\mathrm{OFF})($ Heater3 is OFF) (1)

\section{SIMULATION AND MODEL VALIDATION}

Please use a 9-point Times Roman font, or other Roman font with serifs, as close as possible in appearance to Times Roman in which these guidelines have been set. The goal is to have a 9-point text, as you see here. Please use sans-serif or non-proportional fonts only for special purposes, such as distinguishing source code text. If Times Roman is not available, try the font named Computer Modern Roman. On a Macintosh, use the font named Times. Right margins should be justified, not ragged.

Our model is based on the greenhouse GUESS model that is set for a multi greenhouse chapel which each module is $8.5 \mathrm{~m}$ wide, $34 \mathrm{~m}$ deep and ridge height of $4.5 \mathrm{~m}$. Infiltration rate is 1.1 air changes per hour, and a $\mathrm{U}$ value of $5.76 \mathrm{~W} / \mathrm{m}^{2} . \mathrm{K}$ was used. The model of the plant was set for Douglas seedling plants were started at $0.57 \mathrm{~g}$ dry weight, and harvested $1.67 \mathrm{~g}$ dry weight; a new growing season was recorded at harvest. A set of hourly data for 2015 (1 January to 31 December) weather station of Dar El Beida Algeria and Biskra Algeria [6], was used to validate our model as a CSV file that consists of four columns (global solar radiation, temperature, humidity and wind speed).

The model of the greenhouse was coded using the full version of Windows MATLAB R2012b (8.0.0.783), 64bit (win64) with Simulink. The simulation was performed on a Toshiba laptop. The laptop is equipped with a hard drive $700 \mathrm{~GB}$ and 5 GB of RAM. Simulink model of the parties were made in 
"Accelerator" mode that has first generated a compact representation of Code $\mathrm{C}$ of the diagram, then compiled and executed.

\subsection{Greenhouse Climate Model}

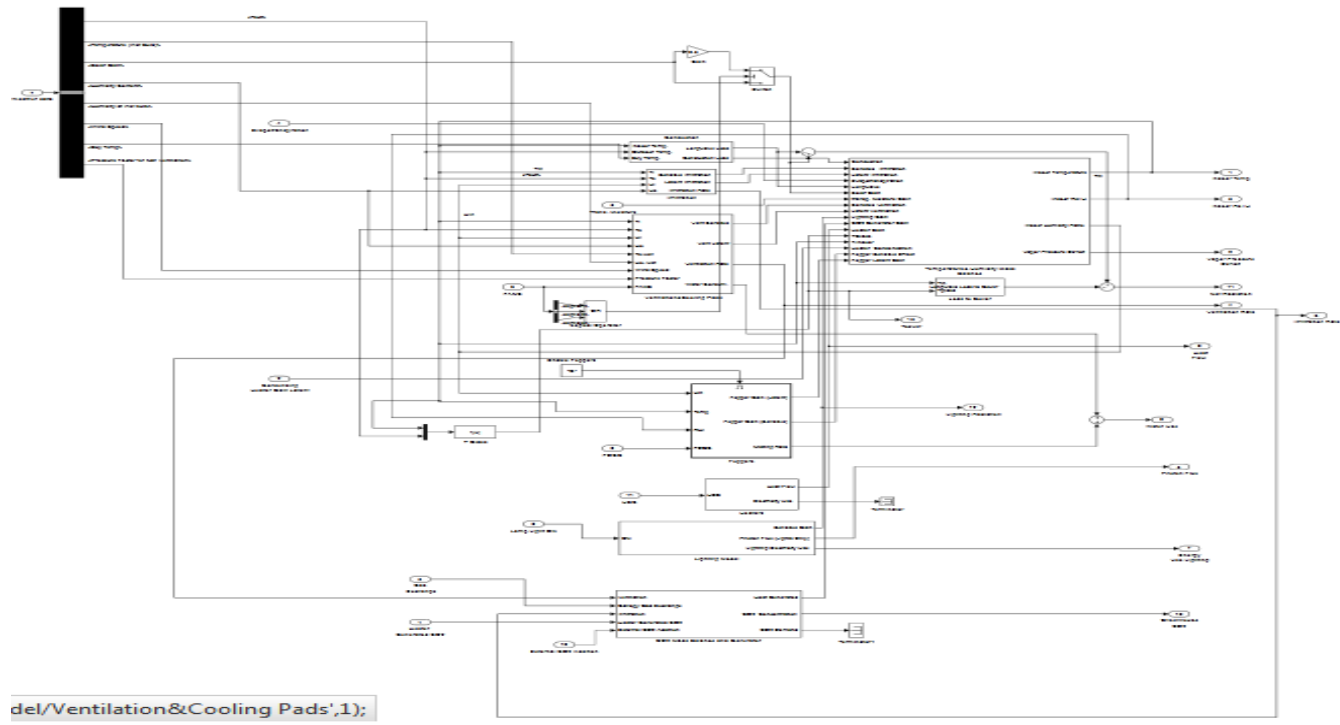

Figure 2. Simulink Representation of the Greenhouse Climate Model

\subsection{Fuzzy Logic Controller Simulation Model of the Greenhouse}

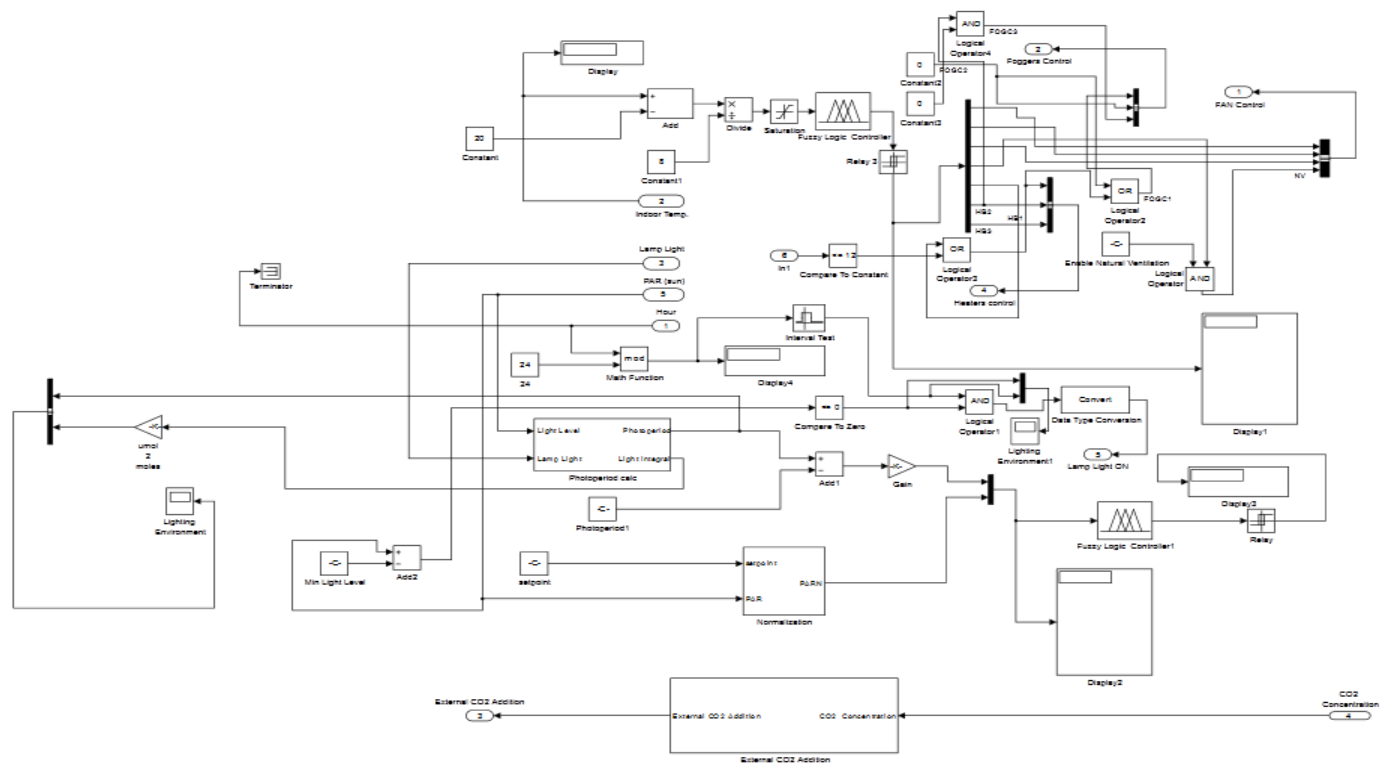

Figure 3. Simulink Representation of the Fuzzy Logic Controller Model

\section{RESULTS}

The simulation results clearly visualize the actual thermo-energy behavior of agricultural greenhouse, applying the model of artificial intelligence, namely the application of fuzzy logic in arid and wetland region [6].

Comparison of Modeling and Simulation Results Management Micro... (Didi Faouzi) 


\subsection{Results Simulation for the wetland region (Dar El Beida)}

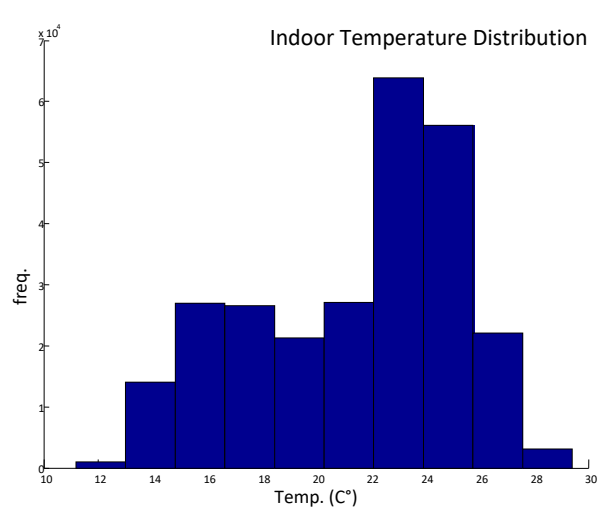

Figure 5. Histogram Shows the Distribution of Indoor Temperature
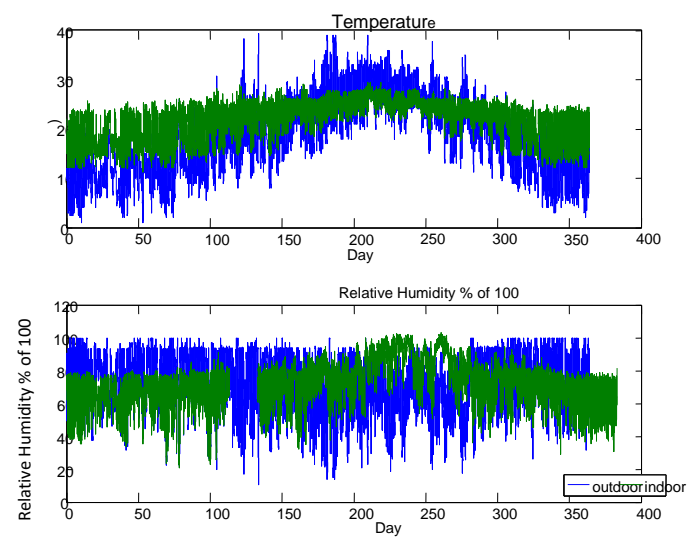

Figure 6. The Evolution of Humidity and Temperature (Interior / Exterior)

\subsection{Results Simulation for the arid region (Biskra)}

It is found in the wetland region (Dar El Beida) that most of the internal temperature values are in the range $14^{\circ} \mathrm{C}$ to $22^{\circ} \mathrm{C}$ for autumn winter period and in the range $20^{\circ} \mathrm{C}$ to $26^{\circ} \mathrm{C}$ for the spring summer period in a large variation the temperature during the winter period is autumn due the heat loss at night, the compensation is insufficient by heating and expensive for this improved thermal insulation of the cover wall is necessary. The improvement of the thermal isolation of the cover may be carried out in practice by the addition of an air bubble plastic layer assembled to the face interior of wall. During the period spring summer the temperature is within the desired range.

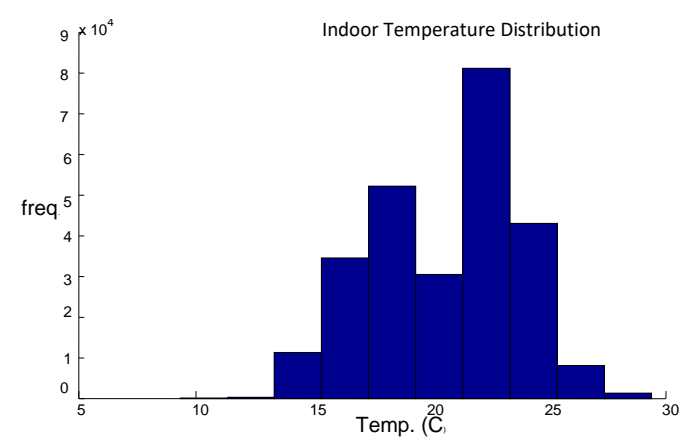

Figure 7. Histogram Shows the Distribution of Indoor Temperature

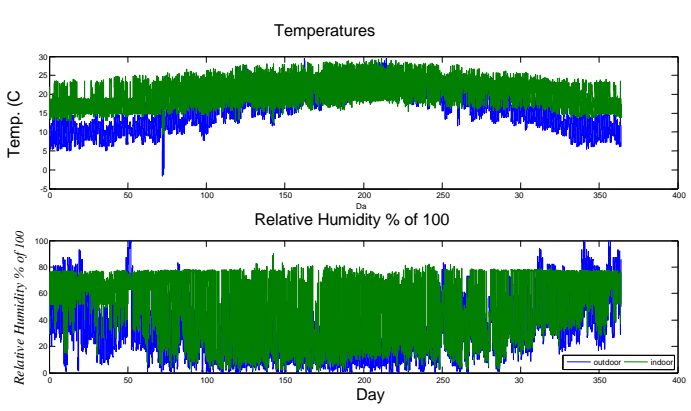

Figure 8. The Evolution of Humidity and Temperature (Interior / Exterior)

The relative humidity is almost in the interval desired during all the year except at the few days of half of the summer because of the important vaporization used for the compensation of the temperature .

But Conversely in the arid region It is found that most of the internal temperature values are in the range $15^{\circ}$ $\mathrm{C}$ to $25^{\circ} \mathrm{C}$ for the autumn winter period, and in the range $20^{\circ} \mathrm{C}$ to $28^{\circ} \mathrm{C}$ for the spring summer period in a large variation the temperature during the winter autumn period is due to heat loss during the night, clearing heating is insufficient and expensive for this improved thermal insulation of the covering wall is necessary.

The improved thermal insulation of the cover may be carried out in practice by the addition of an plastic air bubble layer mounted to the inside wall face. During the period spring summer the temperature is 
almost within the desired range except for half of the summer where the temperature is a little increase. The use of cooling systems and spray is necessary to lower the temperature in the interval longed for

But this solution is insufficient and really expensive, for this purpose we should improve the characteristics of the coverage of the agricultural greenhouse for example thermal insulation or blanket double wall which demonstrates improved efficiency of heating and cooling ... etc. The relative humidity generally stays close to the optimum for all the year except in summer when the humidity drops below threshold due to significant vaporization used for temperature compensation, to resolve this problem adding a screen on the roof of the greenhouse and improving irrigation can compensate the lack of relative humidity in the arid region.

\section{CONCLUSION}

However, our objective is achieved to the extent that it has been shown through modeling and control by the use of fuzzy logic, this area is very difficult because it is a multi control variables which the greenhouse is a biophysical system where parameters are highly correlated as shown by the results. this technique of fuzzy logic that has been adapted to the greenhouse to a promising future for the climate control and management of the greenhouse. For greenhouse growers, it is a preferred approach for structuring and knowledge aggregation and as a means of identification of gaps in the understanding of mechanisms and interactions that occur in the system-greenhouse.

Fuzzy logic is a branch of artificial intelligence, which must point out its advantages and disadvantages. its use has led to quite satisfactory results of the control and regulation perspective.

We remain optimistic in the near future, as to the operation of artificial intelligence, including the use of fuzzy logic which indicates:

a. For the control and regulation of the greenhouse microclimate.

b. By the conservation of energy.

c. For the efficiency of energy use in the greenhouses operation.

d. For improved productivity of crops under greenhouses.

e. In a significant reduction of human intervention.

\section{REFERENCES}

[1] Https://Ecommons.Cornell.Edu/Handle/1813/3437.

[2] Http://Library.Thinkquest.Org/C004535/Calvin_Cycle.Html.

[3] Https://En.Wikipedia.Org/Wiki/Fuzzy_Control_System.

[4] S.D. Dhamakale And S.B. Patil, Fuzzy Logic Approach With Microcontroller for Climate Controlling In Green House, International Journal On Emerging Technologies 2(1): 17-19(2011).

[5] Https://En.Wikipedia.Org/Wiki/Fuzzy_Control_Syste.

[6] Http://Www.Wunderground.Com/Cgibin/Findweather/Getforecast?Qery².

[7] N. Bibi-Triki , S. Bendimemerad , A.Chermitti ,T. Mahdjoub , B. Draoui , A. Abene. Modeling ,Characterization and Analysis of The Dynamic Behavior Of Heat Transfer Through Polyethylene and Glass Wall Of Greenhouses .Elsevier -Physics Procedia 21(2011)67-74

[8] S. Bendimerad , T. Mahdjoub , N. Bibi-Triki , M.Z Bessenouci , B. Draoui , H. Brchar Simulation and Interpretation of the Bibi Ratio $C_{b}($.$) , As A Function of Thermal Parameters of the Low Inertia Polyethylene Wall$ of Greenhouses. Rev Elsevier Physics Procedia 55(2014)157-164

[9] B. Draoui , F. Bounaama , T. Boulard , N. Bibi-Triki. In-Situ Modelization of A Greenhouse Climate Including Sensible Heat, Water Vapor and $\mathrm{Co}_{2}$ Balances. Epd Science ,2013 . Eps Web of Conferences 45.01023(2013) Doi : 10105/Epjconf/201334501023

[10] Abdelhafid Hasni , B.Draoui , T.Boulard , Rachid Taibi , Abdedjebar Hezzab. Evolutionary Algorithms in The Optimization of Greenhouse Climate Model Parameters. International Review on Computers and Software (I.Re.Co.S) ,Vol. 3 , N.6 November 2008 F. Bouaama , K. Lammari , B. Draoui Greenhouse Air Temperature Control Using Fuzzy Pid+I And Neuron Fuzzy Hybrid System Controller International Review of Automatic Control (I.Re.A.Co), Vol. Xx, N. X September 2008

[11] Abdelhafid Hasni , B.Draoui, T.Boulard, Rachid Taibi , Brahim Dennai A. Particle Swarm Optimization Of Natural Ventilation Parameters In A Greenhouse With Continuous Roof Vents Sensor \& Transducers Journal, Vol. 102 , Issue 3 , March 2009 , Pp. 84-93

[12] F. Bouaama , B. Draoui. Greenhouse Environmental Control Using Optimized Mimo Pid Technique Sensors \& Transducers Journal, Vol. 133, Issue 10, October 2011, Pp. 44-52

[13] Khelifa Lammari , F. Bouaama, B. Draoui , Benyoucef Mrah, Mohamed Haidas Ga. Optimization of The Coupled Climate Model of An Order Two Of A Greenhouse . Rev Elsevier Energy Procedia 18 ( 2012 ) 416 - 425

[14] M. Gurbaoui, A. Ed-Dahhak, Y. Elafou, A. Lachhab , L. Belkoura and B. Bouchikhi. Implementation of Direct Fuzzy Controller In Greenhouse Based on Labview ,International Journal of Electrical And Electronics Engineering Studies Vol.1 No.1, Pp.1-13, September 2013 
[15] Mohamed Massour El Aoud And Mostafa Maher. Intelligent Control For A Greenhouse Climate ,International Journal Of Advances In Engineering \& Technology, Sept., 2014. Issn: 22311963

[16] Didi Faouzi , Nacereddine Bibi Triki , Ali Chermitti , Optimizing The Greenhouse Micro-Climate Management By The Introduction Of Artificial Intelligence Using Fuzzy Logic , International Journal Of Computer Engineering \& Technology (Ijcet) ,Volume 7, Issue 3, May-June 2016, Pp. 78-92, Article Id: Ijcet_07_03_007 ,Available Online At Http://Www.Iaeme.Com/Ijcet/Issues.Asp?Jtype=Ijcet\&Vtype=7\&Itype=3.

\section{BIOGRAPHY OF AUTHORS}

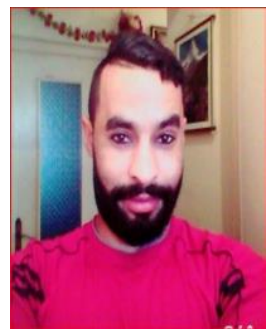

Doctor Didi Faouzi Graduate: DEUA of University degree in Applied cold in 2008 Yahia Fares University of Médéa Algeria, State Engineer HVAC in 2011 from the University of khemis Miliana Algeria, academic Master in Energy and Thermal in 2012 University khemis Miliana Algeria in Mechanical Engineering Degree in 2014 of Yahia Fares University of Médéa Algeria, Master in Energy and Industrial Refrigeration in 2013 Yahia Fares University of Médéa Algeria, $\mathrm{PhD}$ in Physics specialty Renewable Energies during 201

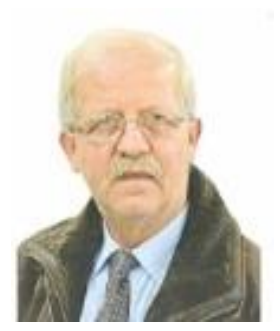

Professor Doctor N. Bibi-Triki Graduate: State Engineer in mechanical engineering technology and industrial equipment of the University of Annaba Algeria, magister holder in physical energy and Doctorate of Science from the University Es Abu Bakr Belkaïd Tlemcen Algeria.

Professor, scientist, head of the National Research Project (NRP) in the field Agriculture, Food, Forestry, Natural and Rural Areas; head of research team in solar thermal material and thermal systems within the Research Unit of Materials and Renewable Energy (URMER) of the University of Tlemcen Algeria.

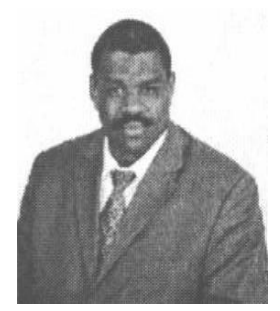

Professor Doctor Draoui Belkacem received MEng from the University of Science and Technology of Oran (Algeria) in January 1988 and PhD thermal degree from University of Nice French in 1994. he is scientific interests are Energy applications in agriculture and horticulture. 